\title{
Novel exocrine glands in the foreleg coxae of Discothyrea ants
}

\author{
Johan Billen ${ }^{1}$, Chung-Chi Lin ${ }^{2}$ and Flavia A. Esteves ${ }^{3}$ \\ 1 Zoological Institute, University of Leuven, Naamsestraat 59, box 2466, B-3000 \\ Leuven, Belgium. e-mail: johan.billen@kuleuven.be \\ 2 National Changhua University of Education, Department of Biology, Changhua 50007, \\ Taiwan, R.O.C. \\ 3 California Academy of Sciences, 55 Music Concourse Dr., San Francisco, CA 94941, \\ U.S.A.
}
Keywords: morphology; histology; ultrastructure; coxa; exocrine glands; Discothyrea sauteri

Running title: novel exocrine glands in the foreleg coxae of Discothyrea ants

Contact address:

Johan Billen, KU Leuven, Zoological Institute, Naamsestraat 59, box 2466, B-3000 Leuven, Belgium

Tel : (32) 16323975

Fax : (32) 16324575

E-mail: johan.billen@kuleuven.be 


\section{ABSTRACT}

Workers, queens and males of all examined Discothyrea species of the 'sauteri group', that have laterally expanded frontal lobes and well-developed antennal scrobes, are characterized by two hairy areas on the outer surface of their procoxae. Histological and ultrastructural examination of $D$. sauteri revealed each of these areas is associated with a novel exocrine gland: the proximal procoxal gland is formed by a cluster of 15 round secretory cells of $34 \mu \mathrm{m}$ with numerous mitochondria, smooth endoplasmic reticulum and Golgi apparatus. Their ducts have a diameter of 0.5-1 $\mu \mathrm{m}$. The distal procoxal gland contains 50 secretory cells of $22 \mu \mathrm{m}$ with numerous vacuoles and lamellar inclusions, and narrow ducts with a diameter of only $0.15-0.2 \mu \mathrm{m}$. The differences in ultrastructural appearance and duct diameter indicates that both glands produce a different but probably pheromonal secretion. The function of the three novel procoxal glands could not yet be determined, although observation of $D$. sauteri workers and queens shows that they make frequent and peculiar leg movements, in which the foreleg basitarsus rubs over the coxal hairy areas. The foreleg basitarsus then rubs the ipsilateral hindleg basitarsus and antenna. As a last step of the sequence, the hindleg basitarsus strokes the gaster. In addition to the occurrence of these novel procoxal glands, histological examination of $D$. sauteri also revealed the presence of yet another novel but smaller procoxal base gland. Ants of the 'testacea group', that have less developed frontal lobes and no antennal scrobes, do not have procoxal hairy areas, although a distinct sculpturation with small pores may occur in the corresponding areas. The related Proceratium japonicum, that has a similar lifestyle as Discothyrea, does not have any of the procoxal glands and does not display the peculiar leg movements as reported for $D$. sauteri. 


\section{INTRODUCTION}

The astonishing diversity of the exocrine system in social insects is well illustrated by the enormous overall number of 149 glands that have been reported so far (Billen and Šobotník, 2015). This variety is further exemplified by the numerous glands that are found in the legs (Billen, 2009 for ants; Billen and Vander Plancken, 2014 for stingless bees; Nijs and Billen 2015, for wasps). In our 2009 review, 20 glands were listed in the legs of ants only (Billen, 2009). This impressive number already needed to be updated to 21 , as yet another "foot-sole gland" was found a few years later in the terminal tarsomeres of the hindlegs of Protanilla wallacei (Billen et al., 2013a). This additional gland was found as we were systematically sectioning all tissues of this rare ant species in order to screen its exocrine repertoire. Besides such systematic screening and coincidental discoveries, the finding of novel leg glands can be the result of peculiar legrelated behaviours that are indicative for the action of glandular secretions, or of the observation with scanning microscopy of specific external regions on the legs such are pore zones that may correspond with the presence of glandular tissue inside the leg (Billen, 2009).

It was the latter case that led us to the discovery of yet additional leg glands, as SEM-examination to document the taxonomy of Discothyrea species from the Malagasy region revealed two special hairy zones with cuticular pores that occur at the outer lateral side of the foreleg coxae in 7 species from Madagascar (Esteves, 2017). As we had embedded thorax material of the Taiwanese $D$. sauteri available, we were able to check their coxae for the presence of glandular tissue. We here describe these exocrine glands that only occur in the foreleg coxae, and also provide a survey with SEM-data on their occurrence among other Discothyrea species from the major geographical regions where they occur. As these glands had not been found before in any other species, they represent novel glands that bring the total number of exocrine glands in ant legs to 24 .

The availability of live colonies of $D$. sauteri allowed us to perform behavioural observations of their peculiar leg movements. These tropical and subtropical ants live in small monogynous colonies with 40-70 workers in rotten wood on the floor of broadleaved forests. They are specialized predators of spider eggs, although no obvious interactions could be noticed between the ants and the spiders under laboratory conditions. We also compared our findings on Discothyrea sauteri with the related Proceratium japonicum, that is also a predator on spider eggs (C.-C. Lin, pers. obs.). contrary to other Proceratium species as $P$. itoi, that feed on non-spider arthropod eggs (Masuko, 2019). 


\section{MATERIAL AND METHODS}

Three colonies of Discothyrea sauteri each with a single dealate queen, approx. 80-100 workers, some males and the various brood stages were collected in Yuchih Township, Nantou County, Taiwan. The ants were kept alive under laboratory conditions $\left(28^{\circ} \mathrm{C}\right.$ with a $12: 12 \mathrm{~L}: \mathrm{D}$ circadian rhythm) on a diet of egg cocoons of various spider species. The tissue pieces examined in this work consisted of the anterior half of the thorax with the two fore coxae attached. The posterior thorax with the midleg and hindleg coxae attached was equally studied for comparison. The distal parts of the legs were cut off at the coxa-trochanter junction, thus allowing easy penetration into the coxae of the various chemicals used during tissue processing. Tissues were fixed in cold $2 \%$ glutaraldehyde (buffered at $\mathrm{pH} 7.3$ with $50 \mathrm{mM}$ sodium cacodylate and $150 \mathrm{mM}$ saccharose) and postfixed in $2 \%$ osmium tetroxide in the same buffer. Dehydration was done through a graded acetone series and was followed by embedding in Araldite. Serial semithin sections with a thickness of $1 \mu \mathrm{m}$ for light microscopy (of 10 workers) were made with a Leica EM UC6 ultramicrotome. They were stained with methylene blue and thionin and viewed with an Olympus BX-51 microscope. Thin sections with a thickness of $70 \mathrm{~nm}$ were double stained with lead citrate and uranyl acetate and viewed with a Zeiss EM900 electron microscope (6 workers).

We used scanning electron microscopy (SEM) to examine the worker, queen and male of the Taiwanese Discothyrea sauteri (8 workers, 1 queen, 5 males) and also several other congeners (see detailed specimen data in Supplementary Material Table 1): D. antarctica (1 worker; New Zealand), D. berlita (1 worker; Mauritius), D. denticulata (1 worker; Peru), D. hewitti (1 worker, 2 queens; South Africa), D. horni (1 worker; Panama), D. humilis (2 workers, Panama), D. sp MG01 (7 workers; Madagascar), D. sp MG02 (3 workers; Madagascar), D. sp MG03 (2 workers; Madagascar), D. sp MG04 (3 workers; Madagascar), D. sp MG05 (2 workers, 1 queen; Madagascar), D. sp MG06 (3 workers; Madagascar), D. sp MG07 (2 workers; Madagascar), D. sp MGm01 (1 male; Madagascar), D. mixta (3 workers, 2 queens, 1 male; Gabon, Uganda), D. oculata (2 workers; Central African Republic, Mozambique), D. poweri (2 workers; South Africa), D. sp SC02 (2 workers; Seychelles), D. sp SC03 (3 workers; Seychelles), D. sculptior (1 worker; Central African Republic), D. testacea (1 worker; United States), and D. sp UG04 (worker; Uganda). For comparison, we studied the procoxa of workers of the related Proceratium japonicum (2 workers for SEM, 4 for light microscopy; Taiwan).

The ants were mounted on aluminum stubs, gold coated, and viewed in a JEOL JSM-6360 SEM (Tokyo, Japan) for D. sauteri, and in a Hitachi SU3500 SEM (Hitachi High-Technologies, Japan) for the other species. In order to properly reveal the pores on the cuticular surface, worker forecoxae of Discothyrea sp. MG03 were soaked for three minutes in a lactophenol solution with glacial acetic acid (Specimen Clearing Fluid, 
BioQuip Products, USA), which was heated to $90^{\circ} \mathrm{C}$. It was then rinsed and sonicated in soapy warm water for five minutes. This lactophenol treatment helped to get rid of all eventual dirt that could otherwise conceal the pores.

Behavioural observations and video imaging of $D$. sauteri were made through a Leica S8APO stereomicroscope equipped with a Panasonic Lumix DMC-GH1 camera. Eventual slow-motion video imaging was achieved using the iMovie post-production software.

\section{RESULTS}

\subsection{Scanning microscopy}

The preliminary observation with scanning electron microscopy of hairy areas with small pores on the foreleg coxa only of several Discothyrea species inspired us to check this in more detail in $D$. sauteri. Of this species, we had live material available, thus allowing histological and ultrastructural examination in addition to scanning electron microscopy. Our observations revealed the occurrence of two hairy areas, that both show pores in the coxal surface between the hair bases. Histological examination using serial semithin sections indicates that these pores correspond with hitherto unknown exocrine glands (Fig. 1). These hairy areas and the underlaying glands do not occur in the related Proceratium japonicum.

The outer lateral surface of the coxa of both forelegs of $D$. sauteri workers, queens and males contains two conspicuous elongate hairy areas (Fig. 2A-D). The smaller proximal hairy area measures approx. $40 \times 20 \mu \mathrm{m}$ and has its longitudinal axis parallel to the connection between the coxal base and the prothorax. The larger hairy area measures approx. $80 \times 30 \mu \mathrm{m}$ and has its longitudinal axis parallel to the long axis of the coxa. Both areas show a dense arrangement of parallel slender hairs that have a length around $30 \mu \mathrm{m}$. The coxal surface at the base of both hairy areas is characterized by the presence of round pores, that have a diameter of $1 \mu \mathrm{m}$ for the proximal area and of 0.25 $\mu \mathrm{m}$ for the distal area (Fig. 2C,E,F).

\subsection{Light microscopy}

Histological examination of serial semithin sections of $D$. sauteri workers revealed the existence of three novel exocrine glands (Fig. 1). The glands correspond with class3 according to the standard classification of insect glands (Noirot and Quennedey, 1974), which means they are formed by bicellular units, each unit comprising a secretory cell and a duct cell. The most proximal part of each coxa contains 5 round secretory cells with a diameter of $18.9 \pm 0.9 \mu \mathrm{m}(\mathrm{N}=6)$. Each cell of this procoxal base gland is 
connected with a slender duct with a diameter of $1 \mu \mathrm{m}$, that winds through the sclerotized coxal cuticle to open at the articulation with the prothorax (Fig. 1, 3A,B). We unfortunately could not obtain thin sections of this gland to perform ultrastructural analysis.

The proximal hairy area is associated with the proximal procoxal gland (Fig. 1, Fig. 3C,D). This gland is formed by a cluster of approx. 15 large round secretory cells with a diameter of $33.9 \pm 3.4 \mu \mathrm{m}(\mathrm{N}=14)$. The ducts that connect these cells to the pores at the base of the hairs of the proximal hairy area have a diameter of $1 \mu \mathrm{m}$ (Fig. $3 C, D)$. The distal hairy area is also associated with gland cells, but their appearance as well as their opening site distinguishes them from the proximal procoxal gland. This distal procoxal gland contains approx. 50 smaller round secretory cells with a diameter of $21.9 \pm 2.8 \mu \mathrm{m}(\mathrm{N}=35)$ (Fig. $3 \mathrm{C}, \mathrm{E})$. The cells that occur near the proximal procoxal gland are more wedge-shaped and have an average length of $22.4 \mu \mathrm{m}$ and a width of $13.7 \mu \mathrm{m}$. The ducts connecting these distal procoxal gland cells to the coxal surface of the distal hairy area are considerably smaller with a diameter around $0.2 \mu \mathrm{m}$ and are therefore hardly visible on semithin sections (white arrows in Fig. 3C,E; see also further under ultrastructural description).

\subsection{Electron microscopy}

Ultrastructural examination of the proximal and distal procoxal glands shows clear differences between both glands, that, in addition to the different opening sites of their duct cells, warrants their designation as two separate glandular formations. The secretory cells of the proximal procoxal gland have a centrally located round nucleus with a diameter of 7-8 $\mu \mathrm{m}$ (Fig. 4A) and an end apparatus with only small amounts of electron-dense material accumulated in the surrounding microvilli (Fig. 4B). The cytoplasm is dominated by numerous mitochondria, with in between them stacks of smooth endoplasmic reticulum (Fig. 4C), Golgi apparatus (Fig. 4D) and a few lamellar bodies (Fig. 4E). The duct cells are characterized by a very reduced cytoplasm and a cuticular canal with an internal diameter around 0.5-1 $\mu \mathrm{m}$, which clearly distinguishes it from the more narrow diameter of the ducts of the distal procoxal gland (Fig. 4B). The distal procoxal gland has secretory cells with a round nucleus with a diameter of 6-7 $\mu \mathrm{m}$. The cytoplasm has a vacuolar appearance due to the presence of numerous spherical secretory vesicles with a diameter between 1 and $3 \mu \mathrm{m}$ (Fig. 5A). The majority of these vesicles is electron-lucid although also some electron-dense vesicles can be found (Fig. 5A,D). The end apparatus shows an interrupted inner cuticular lining, with an obvious accumulation of electron-dense material along its periphery (Fig. 5B,C). Numerous lamellar bodies with a diameter of $0.5-1 \mu \mathrm{m}$ occur in the vicinity of the end apparatus (Fig. 5C). The duct cells have an elongate nucleus of $5 \times 2 \mu \mathrm{m}$, a much reduced cytoplasm and a cuticular duct with an internal diameter of 0.15-0.2 $\mu \mathrm{m}$ (Fig. 
5B,D). Multiple sections through ducts can be seen in a single duct cell, which indicates a sinuous course of the ducts (Fig. 5D).

\subsection{Behavioural observations}

Observation of $D$. sauteri workers as well as queens inside the colony with video imaging revealed that they frequently made quick and peculiar leg movements with their forelegs and hindlegs (Fig. 6; see also videos in Supplementary Material). During these acts, both midlegs are not involved and are used as standing legs, together with the hindleg that is not involved in a particular sequence. A typical sequence starts from the rest position (Fig. 6A) by bending a foreleg at its coxa/trochanter and femur/tibia articulations and moving it upward to rub the inner side of the basitarsus repeatedly over the hairy areas of its coxa (Fig. 6B). The foreleg is then moved backward to touch the similarly folded hindleg, the basitarsi of both legs repeatedly rubbing over each other under varying angles (Fig. 6C-E). As a last step, the foreleg is moved forward again to stroke the antenna, while the hindleg basitarsus is rubbed over the lateral part of the gaster (Fig. 6F); when stroking the antenna, the foreleg basitarsus is moved along the entire antenna from the scape base towards the funicular tip (see videos 3 and 4 in Supplementary Material). We do not know whether the males perform a similar behaviour, as no live males were available in the colonies we studied. Similar leg movements were not observed in Proceratium japonicum.

\subsection{Interspecific comparison}

The 35 extant species validly described for Discothyrea can be divided into two groups of species based on morphological characters of the head. One group, henceforth called the sauteri group, presents frontal lobes expanded laterally and welldeveloped antennal scrobes (Fig. 7), and is represented by ten described species. The other group (henceforth the testacea group) has frontal lobes clearly not as developed as in the sauteri group and the antennal scrobes are absent; it is represented by 25 described species. All the sauteri group species we examined with scanning microscopy have hairy zones on the outer face of the procoxae that conceal cuticular pores (Fig. 7), which are similar to what is seen in $D$. sauteri. The presence of hairy zones could be confirmed in workers, queens and males (Fig. 2: D. sauteri, Fig. 7: D. mixta). The testacea group specimens are bare of such brushes of setae (Fig. 8). We could not evaluate the presence of glandular tissue in the procoxae of any species of the testacea group as we did not have live material available. However, it is worth mentioning that the basoposterior region of the procoxal outer face is distinctively sculptured, and small pores with varying diameter ranging from 0.1-0.5 $\mu \mathrm{m}$ are present in such areas in several specimens (Fig. 8). 


\section{DISCUSSION}

Our finding of 3 novel glands in the foreleg coxae illustrates the astonishing variety of exocrine glands in ants and brings the total number of known glands in their legs to 24. Coxal glands had already been described previously in ants, both epithelial glands belonging to class 1 , and bicellular unit glands belonging to class 3 (Noirot and Quennedey, 1974): the epithelial basicoxal gland is found in the midlegs and hindlegs of many poneromorph species, and produces lubricants to facilitate the articulating movements between the legs and the thorax (Billen and Ito, 2006). The first known "coxal gland" was reported in the three leg pairs of workers of Pachycondyla obscuricornis (now Neoponera obscuricornis) and some other species, and consists of clusters of class- 3 cells with ducts opening through the articulation membranes between the coxa and thorax, and between the coxa and trochanter (Schoeters and Billen, 1993). The cells of the procoxal base gland in Discothyrea that we here describe, however, are associated with ducts that open through the sclerotized proximal coxal cuticle rather than through the soft articulation membrane, and therefore are to be considered as a novel exocrine structure. They may produce lubricant substances to facilitate the frequent movements of the forecoxae (see behavioural observations). The proximal and distal procoxal glands, that are each associated with a conspicuous hairy area on the coxal outer face, because of these unique anatomical features represent novel glands that have not been found in any other ant species.

The different ultrastructural characteristics of the proximal and distal procoxal glands not only show they are different glandular structures, but also indicate that they most likely produce different substances. The presence of numerous clear vesicles, smooth endoplasmic reticulum and abundant lamellar bodies in the distal procoxal gland is in agreement with the elaboration of a lipidic, possibly pheromonal secretion (lamellar bodies are known as lipidic surfactant in lung tissue: Drobne et al., 2008; Ridsdale and Post, 2004). The proximal procoxal gland lacks most of these cytoplasmic elements, although lamellar inclusions also occur, but in considerably lower quantities. A striking difference between both procoxal glands is the diameter of the ducts. The duct diameter of the proximal procoxal measures $0.5-1 \mu \mathrm{m}$, which is the typical size for all class-3 glands regardless of insect size or species (except for Myopias ants, in which gradually enlarging ducts are found: Billen et al., 2013b; Billen and Ito, 2018). Such uniform duct diameter is possibly determined by physicochemical transportation characteristics of the secretory substances. The occurrence of considerably smaller duct diameters of $0.15-$ $0.2 \mu \mathrm{m}$ in the distal procoxal gland, together with the different cytoplasmic appearance of the secretory cells, therefore indicates that both glands produce a different secretion.

Behavioural observation of Discothyrea sauteri revealed that both workers and queens frequently display peculiar leg movements in which their forelegs rub the outer 
surface procoxae at the site where the procoxal glands open, seemingly transferring secretion from the glands onto the foreleg basitarsus. As a result of subsequent leg rubbing between the ipsilateral basitarsi of foreleg and midleg, secretion appears to be transferred further onto the lateral side of the gaster, while the foreleg as a last step of the sequence also rubs the antennae. We unfortunately could not determine which further behaviours are elicited after these gaster and antenna rubbings, nor whether the rubbed secretions originate from the proximal or distal procoxal glands, or both. Smearing of gland secretions from the legs onto the gaster has been documented for the metatibial gland of Diacamma sp., in which these secretions are used during sexual calling behaviour by virgin gamergate workers to attract males (Nakata et al., 1998). Such reproductive function can probably be excluded in Discothyrea, as the procoxal glands not only occur in queens, but also in workers and males. Substrate marking by glands in ant legs is known for the metatibial gland of Crematogaster (Leuthold, 1968), the hindleg basitarsal gland of Onychomyrmex (Hölldobler and Palmer, 1989a) and Prionopelta (Hölldobler et al., 1992), and the footprint gland in Amblyopone (Hölldobler and Palmer, 1989b; Billen et al., 2005). Other examples of rubbing leg gland secretions have been reported for male Polistes dominulus wasps, that mark territorial perches with glands located in the tarsi, tibia and femur of all legs (Beani and Calloni, 1991). The forelegs are well-suited for rubbing and eventual deposit of substances, as they are equipped with a basitarsal brush. This structure is associated with an 'antenna cleaner gland' (Schönitzer et al., 1996), and can serve in hydrocarbon accumulation and circulation through grooming behaviour (Hefetz et al., 2001). The absence of procoxal glands as well as the peculiar leg movements in the related Proceratium japonicum, that also preys on spider eggs (C.-C. Lin, pers. obs.), indicates that the function of the novel glands in Discothyrea is not linked with diet. This assumption is also supported by the absence or at least less developed proxocal glands in species of the testacea group.

While the main focus of this manuscript is the description of the three novel glands, it became clear that we could not generalize our section data of Discothyrea sauteri and the SEM images of other species to the entire genus as Discothyrea is a morphologically non-homogeneous genus. Although species of the testacea group seem to lack the same hairy areas as found in the sauteri group, the presence of pores indicates that also their procoxae may contain gland cells. It will be interesting to verify this once live ants of this testacea group become available.

\section{ACKNOWLEDGEMENTS}

We thank An Vandoren for making the sections and Alex Vrijdaghs for his help in scanning microscopy. Po-Cheng Hsu assisted in the collection and rearing of the Discothyrea sauteri colonies. Brian Fisher, Jean-Jacques Rafanomezantsoa, Chrislain 
Ranaivo, Clavier Randrianandrasana, and Bemaheva Fidelisy collected most of the Malagasy species we used. We extend our thanks to Keiichi Masuko and an anonymous reviewer for valuable comments on the manuscript.

\section{REFERENCES}

Beani, L. and Calloni, C., 1991. Leg tegumental glands and male rubbing behavior at leks in Polistes dominulus (Hymenoptera: Vespidae). J. Chem. Ecol. 4, 449-462.

Billen, J., 2009. Occurrence and structural organization of the exocrine glands in the legs of ants. Arthropod Struct. Dev. 38, 2-15.

Billen, J. and Ito, F., 2006. The basicoxal gland, a new exocrine structure in poneromorph ants (Hymenoptera, Formicidae). Acta Zool. (Stockholm) 87, 291-296.

Billen, J. and Ito, F., 2018. Novel thoracic glands in the ant Myopias hollandi. Arthropod Struct. Dev. 47, 229-237.

Billen, J. and Vander Plancken, L., 2014. Exocrine glands in the legs of the stingless bee Frieseomelitta varia (Lepeletier) (Apidae: Meliponini). Sociobiology 61, 386-392.

Billen, J. and Šobotník, J., 2015. Insect exocrine glands. Arthropod Struct. Dev. 44, 399400.

Billen, J., Bauweleers, E., Hashim, R. and Ito, F., 2013a. Survey of the exocrine system in Protanilla wallacei (Hymenoptera, Formicidae). Arthropod Struct. Dev. 42, 173183.

Billen, J., Stroobants, Z., Wenseleers, T., Hashim, R. and Ito, F., 2013b. Diversity and morphology of abdominal glands in workers of the ant genus Myopias (Formicidae, Ponerinae). Arthropod Struct. Dev. 42, 165-172.

Billen, J., Thys, B., Ito, F. and Gobin, B., 2005. The pretarsal footprint gland of the ant Amblyopone reclinata (Hymenoptera, Formicidae) and its role in nestmate recruitment. Arthropod Struct. Dev. 34, 111-116.

Drobne, D., Milani, M., Lešer, V., Tatti, F., Zrimec, A., Žnidaršič, N., Kostanjšek, R. and Štrus, J., 2008. Imaging of intracellular spherical lamellar structures and tissue gross morphology by a focused ion beam/scanning electron microscope (FIB/SEM). Ultramicroscopy 108, 663-670.

Esteves, F.A., 2017. To lump or to split: pitfalls of using morphology for delimiting Discothyrea species. Abstract XXIII Simpósio de Mirmecologia, Curitiba, PR, Brazil 2017, 47.

Hefetz, A., Soroker, V., Dahbi, A., Malherbe, M.C. and Fresneau, D., 2001. The front basitarsal brush in Pachycondyla apicalis and its role in hydrocarbon circulation. 
Chemoecology 11, 17-24.

Hölldobler, B. and Palmer, J.M., 1989a. A new tarsal gland in ants and the possible role in chemical communication. Naturwissenschaften 76, 385-386.

Hölldobler, B. and Palmer, J.M., 1989b. Footprint glands in Amblyopone australis (Formicidae, Ponerinae). Psyche 96, 111-121.

Hölldobler, B., Obermayer, M. and Wilson, E.O., 1992. Communicationin the primitive cryptobiotic ant Prionopelta amabilis (Hymenoptera: Formicidae). J. Comp. Physiol. 170A, 9-16.

Leuthold, R.H., 1968. A tibial gland scent-trail and trail-laying behavior in the ant Crematogaster ashmeadi Mayr. Psyche 75, 233-248.

Masuko, K., 2019. Predation on non-spider arthropod eggs and colony bionomics of the ant Proceratium itoi (Hymenoptera: Formicidae). Annls Entomol. Soc. Am. 20, 1-7.

Nakata, K., Tsuji, K., Hölldobler, B. and Taki, A., 1998. Sexual calling by workers using the metatibial glands in the ant, Diacamma sp., from Japan (Hymenoptera: Formicidae). J. Insect Behav. 11, 869-877.

Nijs, C. and Billen, J., 2015. Exocrine glands in the legs of the social wasp Vespula vulgaris. Arthropod Struct. Dev. 44, 433-443.

Noirot, C. and Quennedey, A., 1974. Fine structure of insect epidermal glands. Annu. Rev. Entomol. 19, 61-80.

Ridsdale, R. and Post, M., 2004. Surfactant lipid synthesis and lamellar body formation in glycogen-laden type II cells. Am. J. Physiol. - Lung Cell. Mol. Physiol. 287, L743L751.

Schoeters, E. and Billen, J., 1993. Glandes coxales de Pachycondyla obscuricornis (Formicidae, Ponerinae). Actes Coll. Insectes Soc. 8, 183-186.

Schönitzer, K., Dott, H. and Melzer, R.R., 1996. The antenna cleaner gland in Messor rufitarsis (Hymenoptera, Formicidae). Tissue Cell 28, 107-113. 


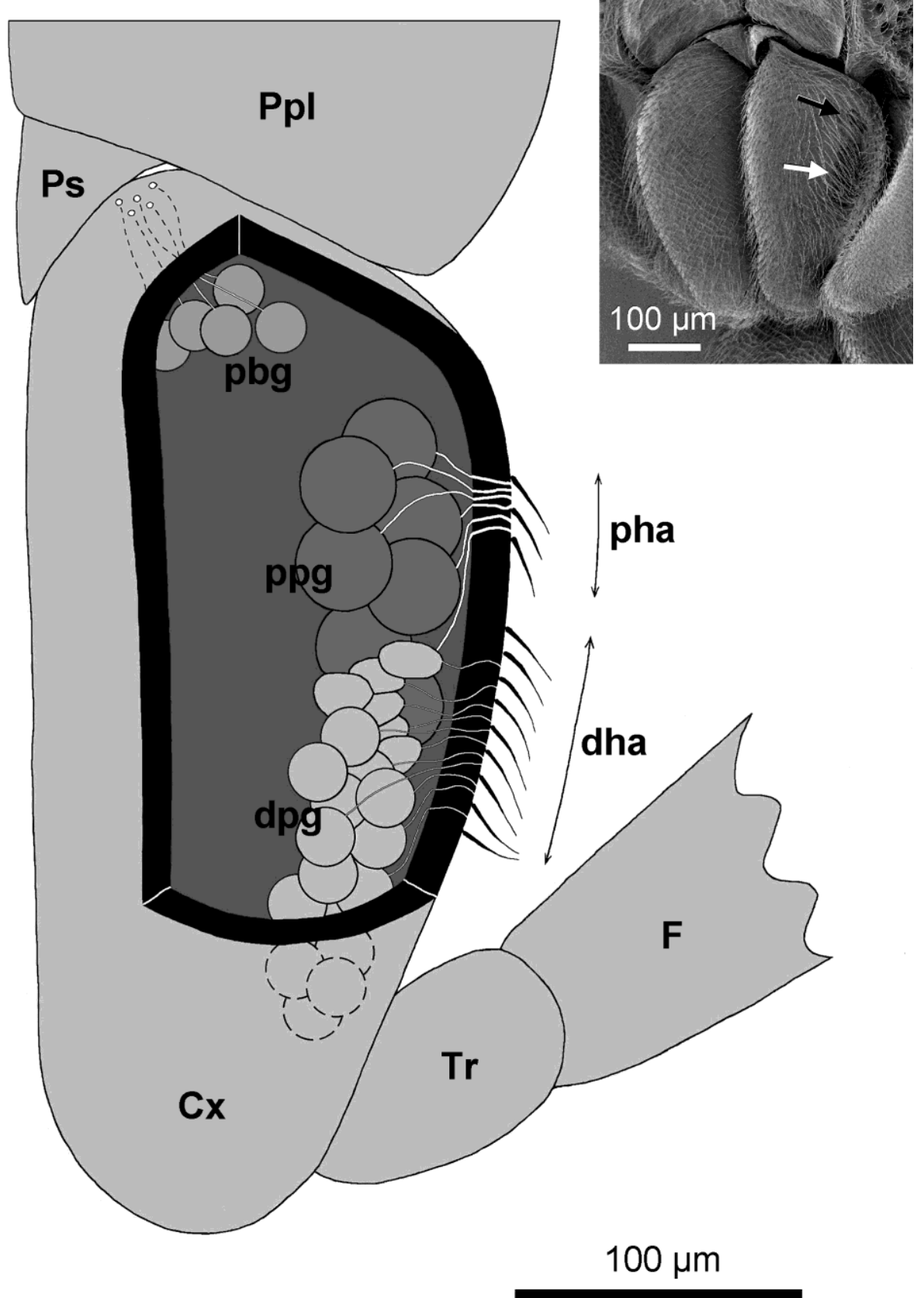

Fig. 1. Schematical illustration of forecoxa with upper quarter part removed, drawn to scale, showing the three novel exocrine glands (dpg: distal procoxal gland, pbg: procoxal base gland, ppg: proximal procoxal gland). Cx: coxa, dha: distal hairy area, F: femur, pha: proximal hairy area, Ppl: propleural plate, Ps: prosternum, Tr: trochanter. Inset shows location of proximal (black arrow) and distal hairy areas (white arrow) on foreleg coxa of $D$. sauteri worker. 

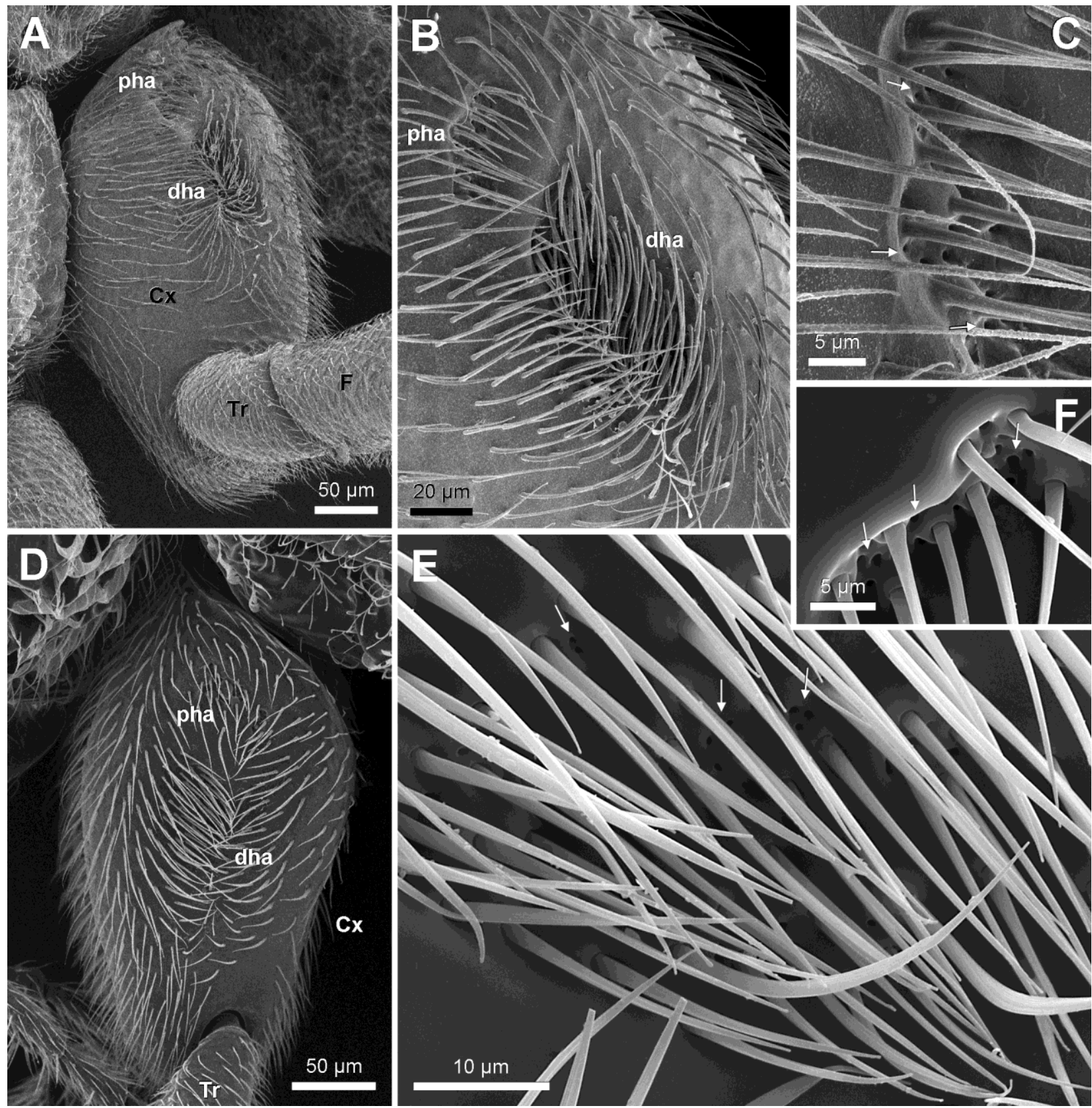

Fig. 2. Scanning micrographs of hairy areas on outer forecoxa surface. A. General view of coxa of $D$. sauteri queen (Cx: coxa, dha: distal hairy area, $F$ : femur, pha: proximal hairy area, Tr: trochanter). B. View of proximal and distal hairy areas in $D$. sauteri worker. C. Detail of proximal hairy area showing small pores (arrows) on coxal surface in $D$. sauteri worker. D. General view of coxa of $D$. sauteri male. E. Distal hairy area with small pores (arrows) of $D$. sp MG03 worker after lactophenoltreatment. F. Proximal hairy area with larger pores (arrows) of $D$. sp MG03 worker after lactophenol-treatment. 


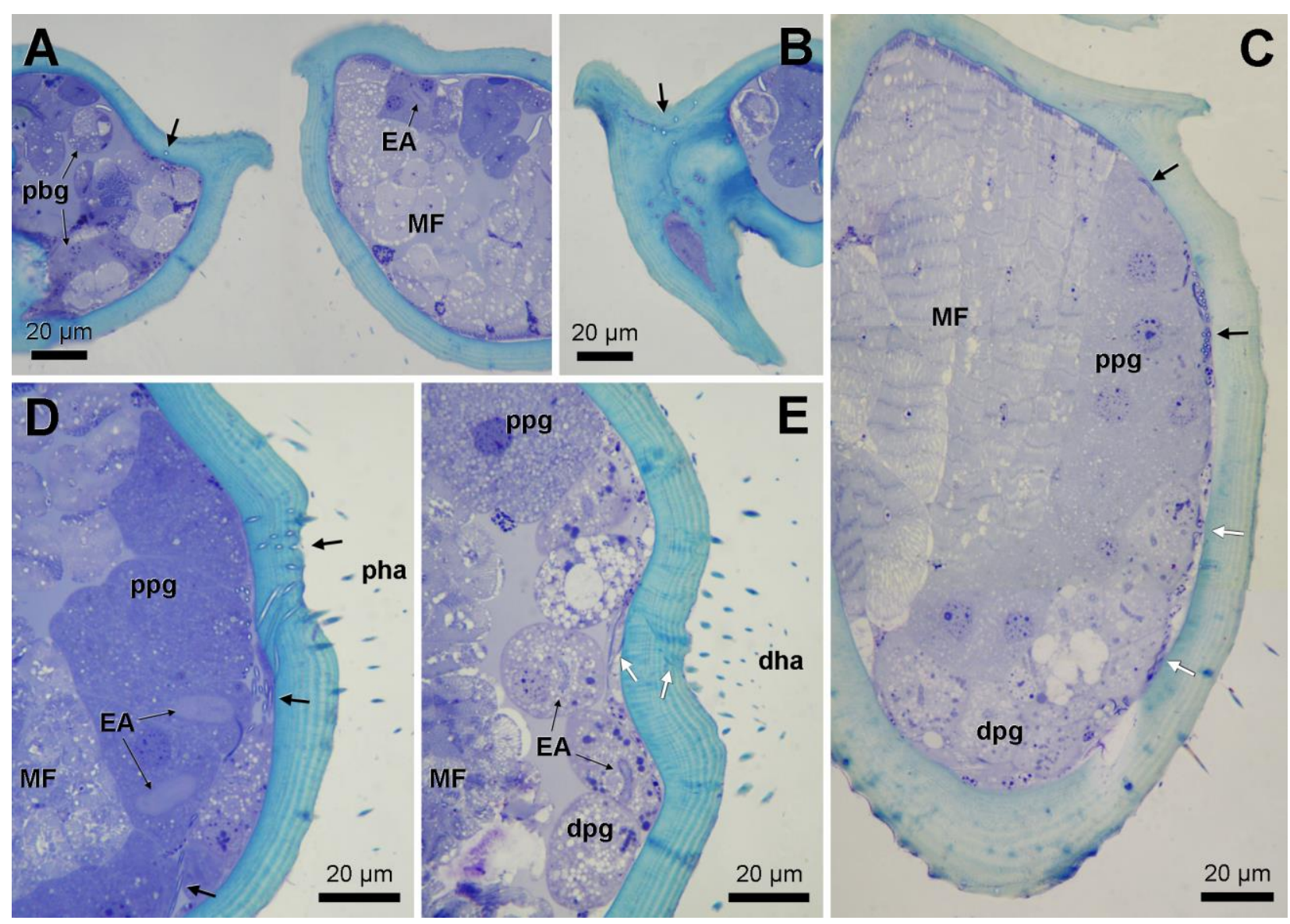

Fig. 3. Semithin section images through forecoxa of $D$. sauteri workers. A. Cross section of proximal part of both coxae, showing cells of procoxal base gland (pbg). EA indicates end apparatus, arrow shows ducts in coxal cuticle. MF: muscle fibres. B. Cross section of right coxa near articulation with prothorax, note ducts in coxal cuticle (arrow). C. Longitudinal section of coxa showing larger cells of proximal procoxal gland (ppg) and their larger ducts (black arrow), and smaller vacuolated cells of distal procoxal gland (dpg) and their smaller ducts (white arrows). D. Cross section at level of proximal hairy area (pha) with cells of proximal procoxal gland and their large ducts (black arrows). E. Cross section at level of distal hairy area (dha) with cells of distal procoxal gland and their small ducts (white arrows). 


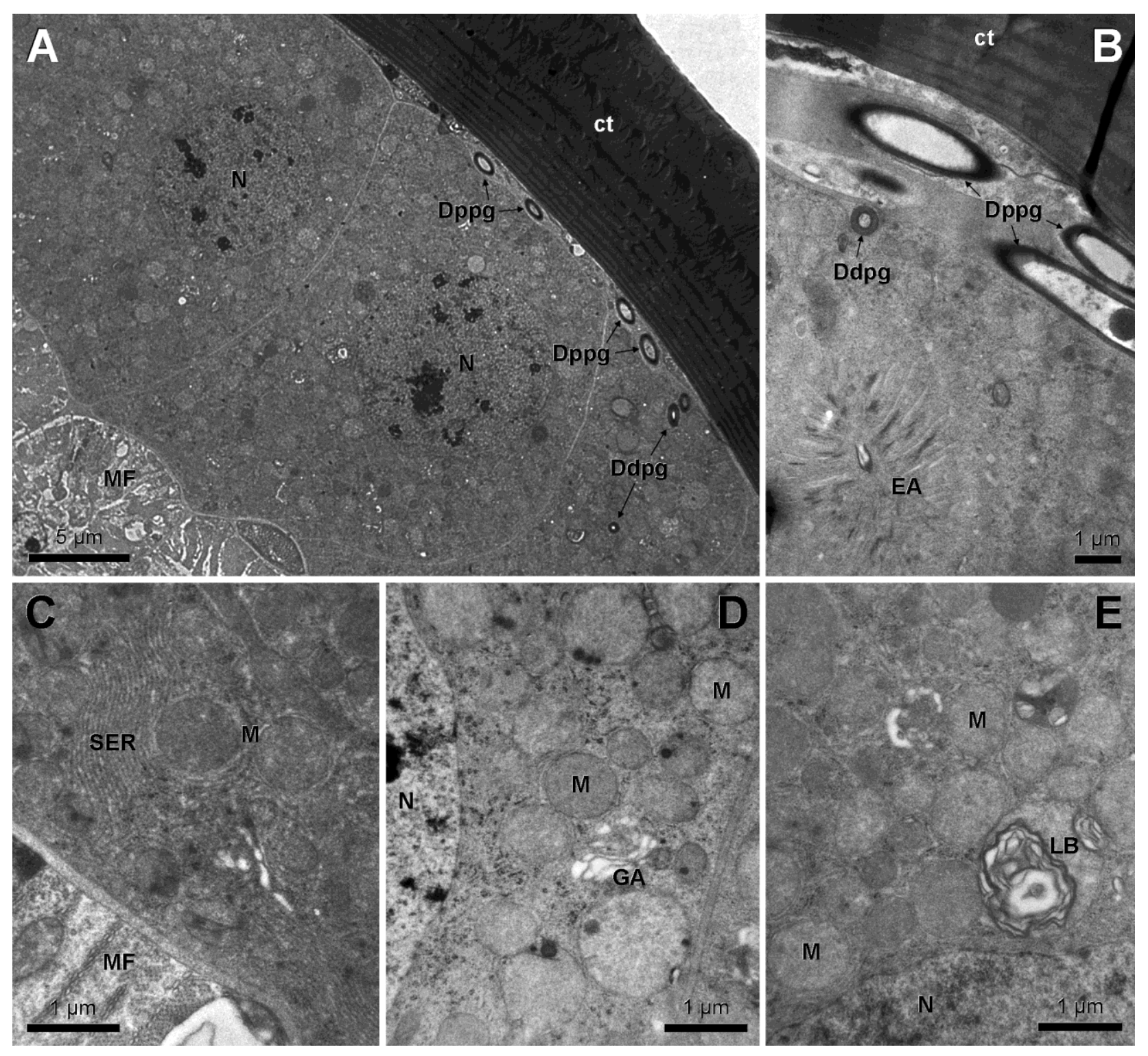

Fig. 4. Electron micrographs of proximal procoxal gland: A. General view of large secretory cells and ducts of proximal procoxal gland (Dppg) having clearly larger diameter than ducts of distal procoxal gland (Ddpg). B. Detail of ducts with different diameter and of end apparatus (EA) in secretory cell. C-E. Cytoplasmic details of secretory cells showing smooth endoplasmic reticulum (C), abundant large mitochondria and Golgi apparatus (D) and lamellar bodies (E). ct: cuticle, MF: muscle fibres, N: nucleus. 


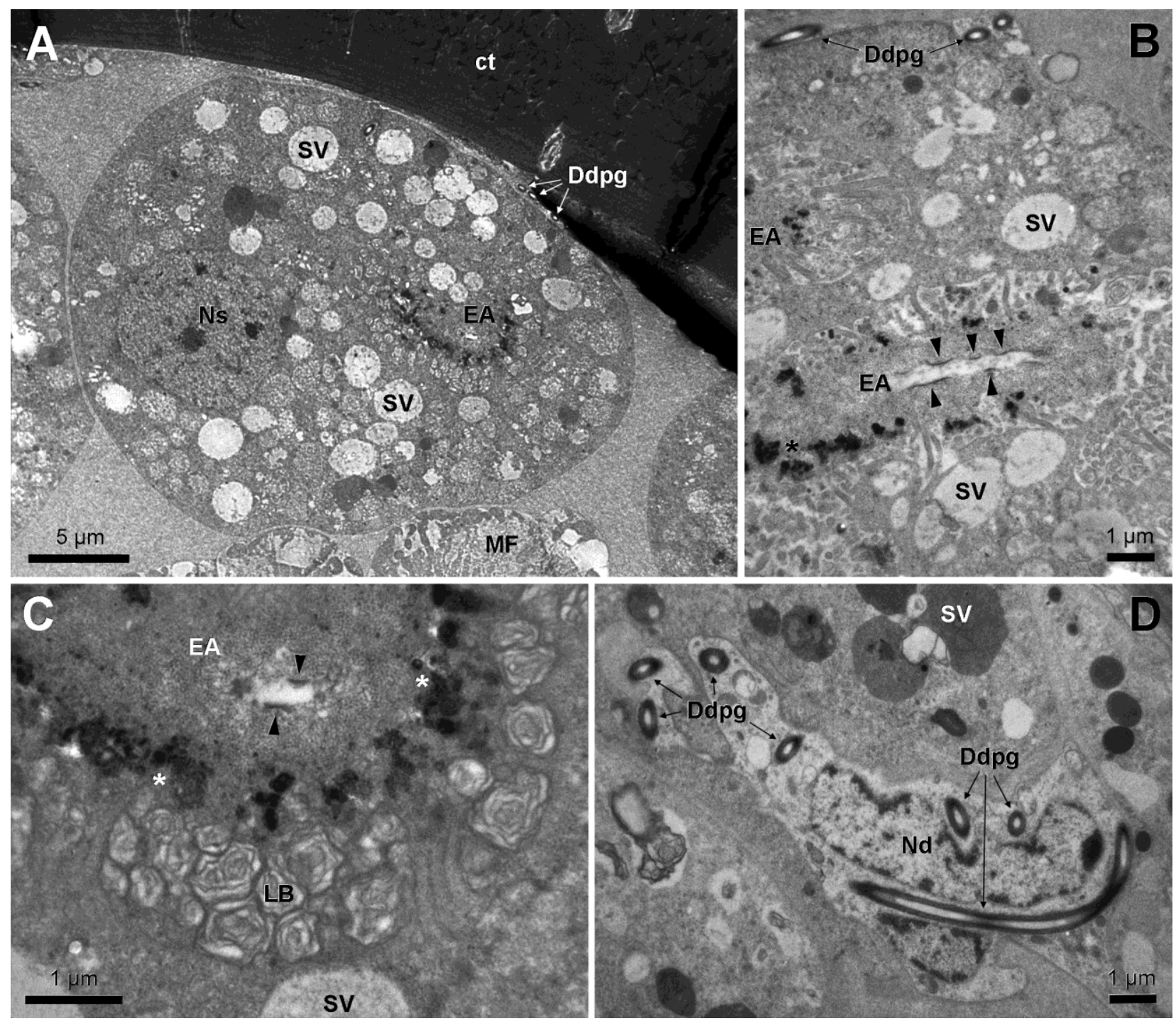

Fig. 5. Electron micrographs of distal procoxal gland: A. General view of secretory cell with round nucleus (Ns), numerous large secretory vesicles (SV) and end apparatus (EA), and ducts with small diameter (Ddpg). B,C. Details of end apparatus, showing interrupted inner cuticular lining (arrowheads) and accumulation of electron-dense material (asterisks) and lamellar bodies (LB) surrounding end apparatus. D. Detail of duct cell with nucleus $(\mathrm{Nd})$ and multiple sections through sinuous cuticular duct. ct: cuticle, MF: muscle fibres. 

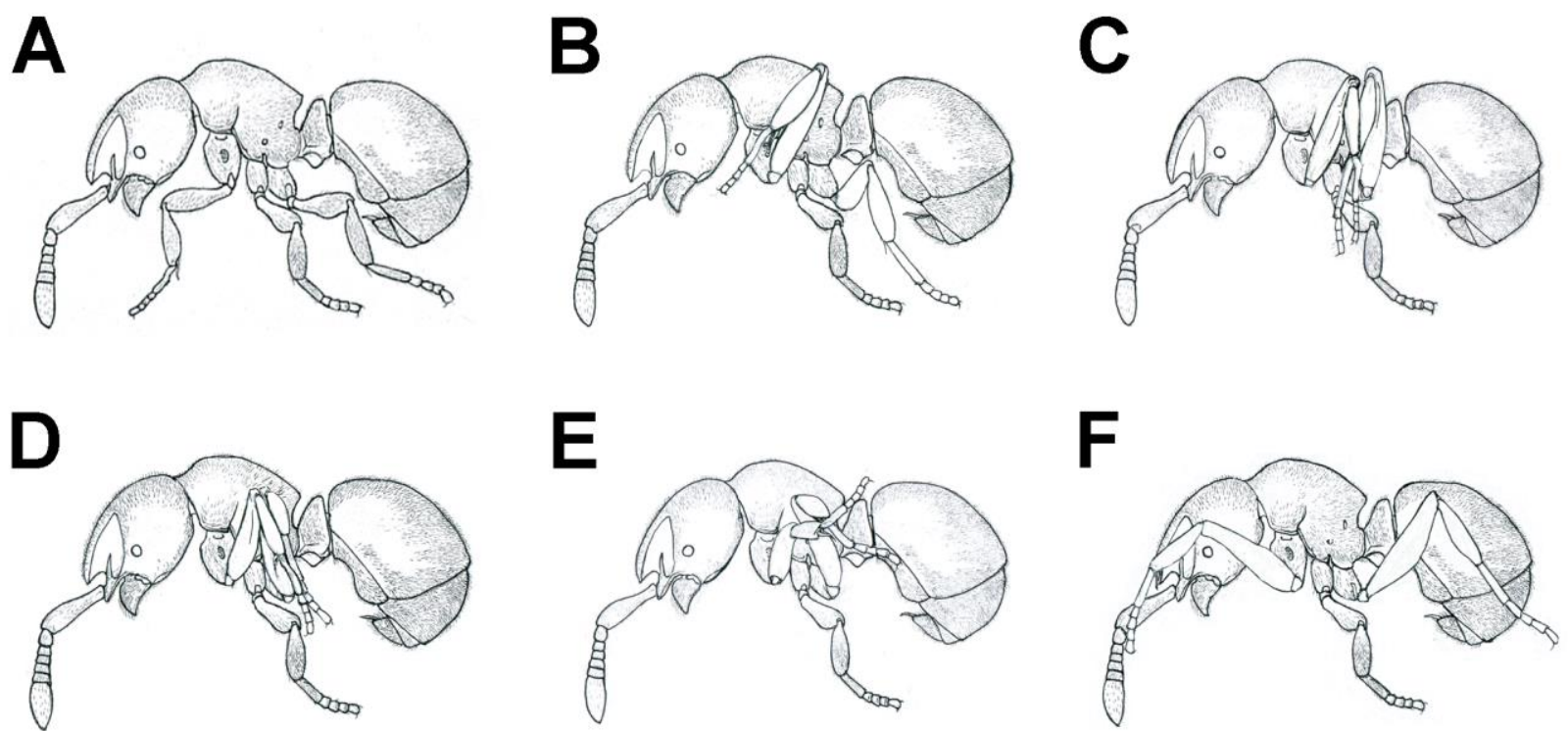

Fig. 6. Schematical illustration, based on video imaging, of sequential leg movements of $D$. sauteri worker (here shown for the left side). Starting from rest position $(A)$, the foreleg is bent and moved upward to rub the inner side of the basitarsus over the hairy areas of the procoxa (B). The basitarsi of foreleg and hindleg are rubbed against each other $(\mathrm{C}-\mathrm{E})$, the sequence ends with the foreleg stroking the antenna and the hindleg basitarsus rubbing over the lateral part of the gaster $(F)$. Note the midleg is not involved in any movement, and is used as a standing leg.
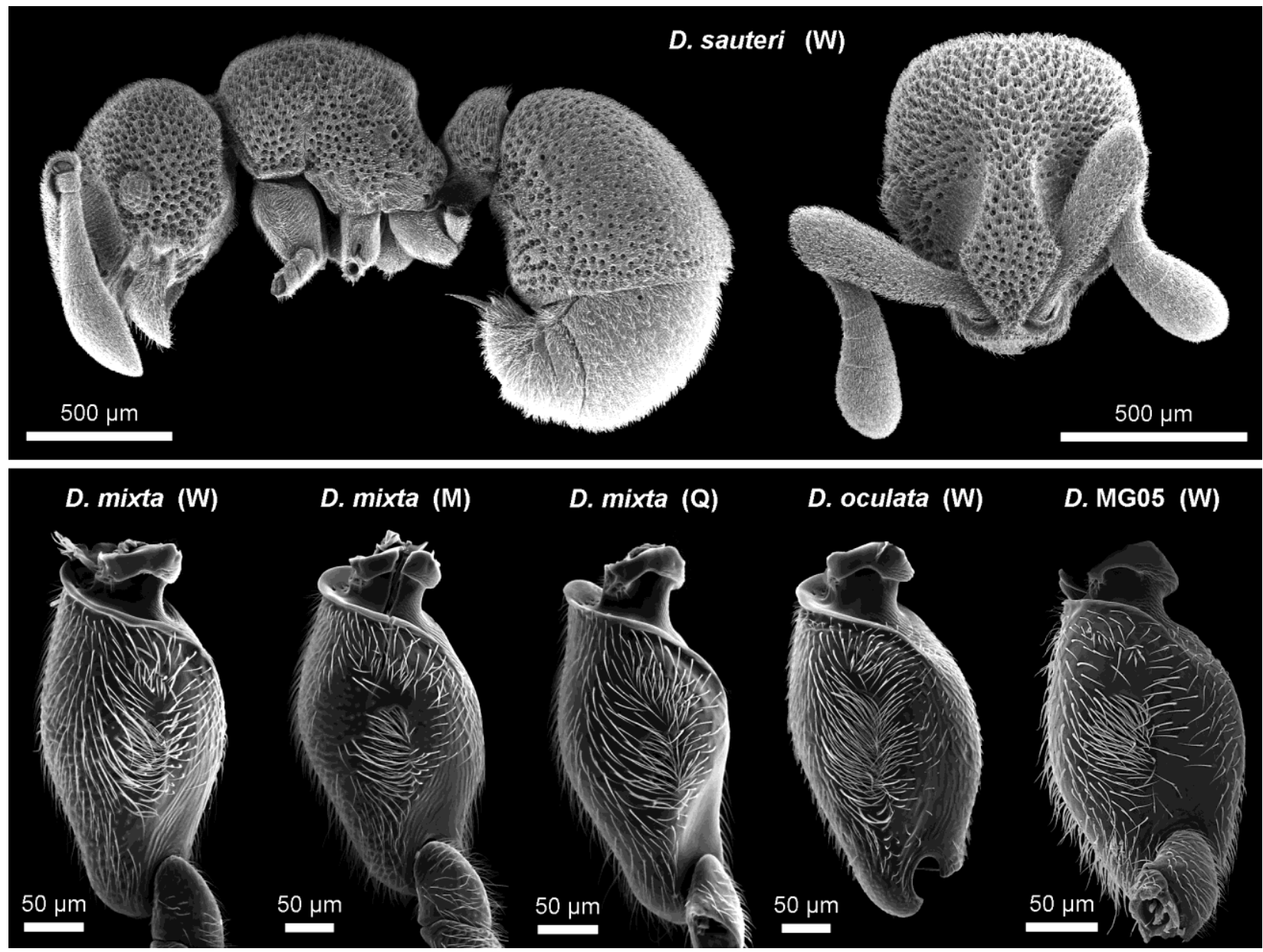

Fig. 7. Scanning micrographs of profile view and frontal head view of Discothyrea sauteri 
worker showing expanded lateral frontal lobes (upper figures) and forecoxae of different species and castes of the sauteri-group, showing the well-developed hairy areas (lower figures; W: worker, M: male, Q: queen).
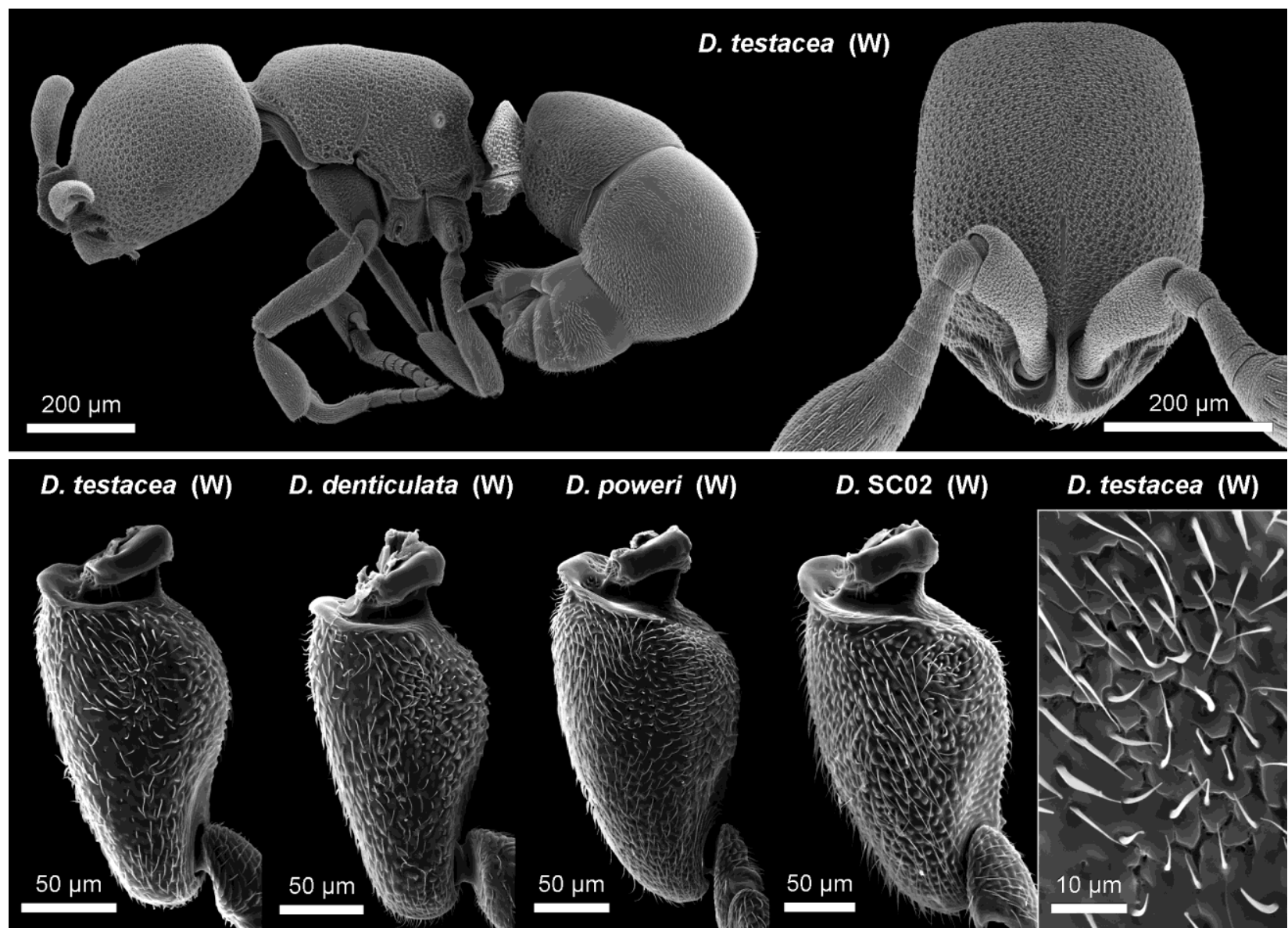

Fig. 8. Scanning micrographs of profile view and frontal head view of Discothyrea testacea worker showing reduced lateral frontal lobes (upper figures) and forecoxae of workers of different species of the testacea-group, showing the poorly-developed or absent hairy areas (lower figures). The lower right detail image shows a disorderly hairy pattern only on the procoxal outer face, although small pores can be recognized.

\section{SUPPLEMENTARY MATERIAL}

Video 1: leg movements of $D$. sauteri worker, shown at normal speed.

Video 2: leg movements of $D$. sauteri worker, shown in slow motion (4x slower).

Video 3: leg movements of $D$. sauteri queen, shown at normal speed.

Video 4: leg movements of $D$. sauteri queen, shown in slow motion (4x slower).

Table 1. Detailed list of ant material studied. 